\title{
Optimal Reactive Power Dispatch untuk Meminimalkan Rugi Daya Menggunakan Flower Pollination Algorithm
}

\author{
Fredi Prima Sakti ${ }^{1}$ dan Jimmy Trio Putra ${ }^{2}$ \\ ${ }^{1}$ Program Studi Teknik Elektro, Fakultas Teknologi Informasi dan Elektro, Universitas Teknologi Yogyakarta \\ Jalan Siliwangi, Jl. Ringroad Utara, Daerah Istimewa Yogyakarta, 55285, Indonesia \\ ${ }^{2}$ Program Studi Teknologi Listrik, Departemen Teknik Elektro dan Informatika, Sekolah Vokasi Universitas Gadjah Mada \\ Jalan Yacaranda, Caturtunggal, Daerah Istimewa Yogyakarta, 55281, Indonesia
}

fredipsakti@staff.uty.ac.id', jimmytrioputra@ugm.ac.id ${ }^{2}$

\begin{abstract}
This paper presents the Flower Pollination Algorithm (FPA) metaheuristic used to solve the Optimal Reactive Power Dispatch (ORPD) problem. ORPD is a non-linear optimization problem in the electric power system that regulates the generation of reactive power at the generator to minimize the real power loss on the transmission line while maintaining all parameters at the allowable value. In this case the FPA algorithm is used to find the minimum power loss by adjusting the voltage magnitude value of the generator, the transformer tap settings, and the reactive power compensator value in the system while maintaining the magnitude of the bus voltage, active and reactive power at the generator, and the channel capacity remains at its safe limit. ORPD is applied to the IEEE-30 Bus system test consisting of 8 generating units, 4 transformers, 9 reactive power compensators and 41 channels. The system has a load of 283.4 MW and 126.2 MVAR. The results after being optimized using FPA shows the power loss in the channel is reduced to 4,895 MW or reduced by $15.89 \%$. The results of optimization using FPA showed better results compared to Genetic Algorithm and Particle Swarm Optimization.
\end{abstract}

Keywords - Optimal Reactive Power Dispatch, power loss, voltage magnitude, Flower Pollination Algorithm

\begin{abstract}
Abstrak- Makalah ini menampilkan algoritma metaheuristic Flower Pollination Algorithm (FPA) yang digunakan untuk menyelesaikan permasalahan Optimal Reactive Power Dispatch (ORPD). ORPD adalah masalah optimasi non-linear pada sistem tenaga listrik yang mengatur pembangkitan daya reaktif pada generator untuk meminimalkan rugi daya nyata pada saluran transmisi dengan tetap menjaga semua parameter berada pada nilai yang diizinkan. Pada kasus ini algoritma FPA digunakan untuk mencari rugi daya yang paling minimum dengan mengatur nilai magnitud tegangan pada generator, setting tap trafo, dan nilai kompensator daya reaktif yang ada pada sistem dengan tetap menjaga nilai magnitud tegangan bus, daya aktif dan reaktif pada generator, serta kapasitas saluran tetap berada pada batas amannya. ORPD diterapkan pada tes sistem IEEE-30 Bus yang terdiri dari 8 unit pembangkit, 4 transformator, 9 kompensator daya reaktif, dan 41 saluran. Sistem memiliki beban 283,4 MW dan 126,2 MVAR. Hasil setelah dioptimasi menggunakan FPA menunjukkan rugi daya pada saluran berkurang menjadi 4,895 MW atau berkurang sebesar 15,89\%. Hasil optimasi menggunakan FPA menunjukkan hasil yang lebih baik dibandingkan dengan Algorirma Genetik dan Particle Swarm Optimization.
\end{abstract}

Kata kunci-Optimal Reactive Power Dispatch, rugi daya, magnitud tegangan, Flower Pollination Algorithm

\section{PENDAhUluan}

Prinsip operasi sistem tenaga listrik yaitu kualitas, andal, dan ekonomis. Kualitas dimaknai dengan listrik yang dihasilkan harus memiliki nilai yang sesuai standar, seperti tegangan dan frekuensi. Andal dimaknai dengan transfer energi listrik dari pembangkit hingga ke beban mengalami keberhasilan tanpa pemadaman. Sedangkan ekonomis yaitu menjalankan operasi sistem tenaga listrik dengan biaya yang ekonomis [1].

Salah satu penyebab biaya operasi yang tinggi yaitu besarnya rugi-rugi daya pada saluran transmisi. Semakin besar rugi daya tersebut, artinya semakin besar pula daya yang terbuang. Oleh karena itu meminimalkan rugi-rugi daya menjadi perlu untuk dilakukan [2].

Kerugian sistem dapat diminimalkan melalui redistribusi daya reaktif pada sistem salah satunya dengan Optimal Reactive Power Dispatch (ORPD) [3]. ORPD merupakan masalah optimasi non-linear dengan mengatur pembangkitan daya reaktif untuk meminimalkan rugi daya nyata pada saluran transmisi, menjaga semua nilai tegangan dalam batas yang diizinkan, sekaligus memuaskan sejumlah batasan baik yang berbentuk persamaan maupun pertidaksamaan.

Pengaturan pembangkitan daya reaktif pada suatu sistem tenaga listrik merupakan salah satu peran yang penting untuk operasi dan kontrol sistem tenaga listrik. Hal tersebut 
dilakukan agar menghasilkan operasi yang efisien. Pengaturan daya reaktif dapat mengurangi kerugian daya pada saluran transmisi. Pengaturan daya reaktif dapat dilakukan dengan mengatur variabel kontrol daya reaktif seperti tegangan generator, pengaturan tap transformator, dan sumber daya reaktif lainnya. Sumber daya reaktif selain dari generator dapat diperoleh dari bank kapasitor maupun perangkat Flexible Alternating Current Transmission System (FACTS) [4]-[7].

Pada penelitian ini Flower Pollination Algorithm (FPA) akan digunakan untuk memecahkan masalah ORPD. FPA merupakan algoritma yang dikembangkan oleh Xin-She Yang pada 2012 [8]. FPA merupakan algoritma meta-heuristik yang terinspirasi oleh fenomena alam terkait dengan penyerbukan bunga. Penggunaan metode FPA untuk menyelesaikan masalah ORPD telah dilakukan oleh beberapa peneliti sebelumnya dengan fungsi tujuan yang berbeda [9]-[13].

FPA dipilih untuk menyelesaikan permasalahan ORPD karena algoritma tersebut diklaim mempunyai performa yang lebih baik dari algoritma yang saat ini banyak digunakan seperti Particle Swarm Optimization (PSO) dan Genetic Algorithm (GA) jika dilihat dari jumlah iterasi dan rating keberhasilannya dalam mencari global optimum [8]. Penelitian dilakukan pada tes sistem IEEE 30 bus agar dapat membandingkan dengan beberapa algoritma lainnya pada permasalahan ORPD.

\section{FORMUlasi OPTIMAL REACTIVE POWER DISPATCH (ORPD)}

Fungsi obyektif pada permasalahan ini yaitu meminimalkan rugi daya saluran ditambah dengan fungsi penalti. Rugi daya saluran merupakan selisih antara daya yang dikirim dari suatu bus dengan daya yang diterima di bus lainnya dengan melewati suatu saluran transmisi. Fungsi penalti digunakan untuk menjaga agar nilai yang dihasilkan tetap sesuai dengan batas-batas yang diizinkan. Secara umum, fungsi didefinisikan sebagai:

$$
\text { Min Ploss }=\sum_{\mathrm{k}=1}^{\mathrm{n}_{\beta}} \mathrm{SL}_{k}+\text { Penalti }
$$

Dimana $\mathrm{SL}_{\mathrm{k}}$ merupakan rugi daya pada saluran ke-k, nb merupakan banyaknya saluran yang ada pada sistem. Penalti akan dijelaskan pada (10).

\section{A. Variabel Kontrol}

Variabel kontrol adalah variabel yang dapat dimodifikasi yang berfungsi untuk mendapatkan nilai fungsi objektif yang paling minimal. Dalam hal ini fungsi obyektif yang dicari yaitu rugi daya aktif pada saluran. Nilai dari variabel kontrol tidak boleh melebihi ambang batas yang dimiliki oleh setiap variabel kontrol. Variabel kontrol pada permasalahan ORPD ini yaitu daya reaktif yang dibangkitkan generator, magnitud tegangan yang dibangkitkan generator, pengaturan tap trafo, dan daya reaktif yang dikompensasi dari kapasitor shunt.

\section{B. Batasan Fungsi Obyektif}

Batasan pada ORPD diklasifikasikan menjadi kendala bentuk persamaan dan batasan bentuk pertidaksamaan. Secara rinci akan dijelaskan di bagian selanjutnya.

\section{1) Batasan Bentuk Persamaan}

Dalam kasus ini ingin didapatkan rugi daya pada saluran yang seminimal mungkin, namun demikian harus dipastikan bahwa total daya yang dibangkitkan harus sama dengan total beban ditambah dengan rugi daya pada saluran transmisi secara keseluruhan. Batasan bentuk persamaan pada kasus ORPD sering dikenal sebagai persamaan keseimbangan daya (Power Balance Equation) [3]yang dijelaskan sebagai berikut:

$$
\begin{gathered}
\mathrm{P}_{\mathrm{Gi}}-\mathrm{P}_{\mathrm{Di}}-\sum_{\mathrm{j}=1}^{\mathrm{n}_{\mathrm{b}}} \mathrm{V}_{\mathrm{i}} \mathrm{V}_{\mathrm{j}}\left(\mathrm{g}_{\mathrm{ij}} \cos \theta_{\mathrm{ij}}+\mathrm{b}_{\mathrm{ij}} \sin \theta_{\mathrm{ij}}\right)=0 \\
\mathrm{Q}_{\mathrm{Gi}}-\mathrm{Q}_{\mathrm{Di}}-\sum_{\mathrm{j}=1}^{\mathrm{n}_{\mathrm{b}}} \mathrm{V}_{\mathrm{i}} \mathrm{V}_{\mathrm{j}}\left(\mathrm{g}_{\mathrm{ij}} \sin \theta_{\mathrm{ij}}+\mathrm{b}_{\mathrm{ij}} \cos \theta_{\mathrm{ij}}\right)=0
\end{gathered}
$$

Keterangan:

$\mathrm{P}_{\mathrm{Gi}}=$ Total daya aktif yang dibangkitkan oleh generator pada bus-i.

$\mathrm{P}_{\mathrm{Di}}=$ Total daya aktif beban pada bus $-\mathrm{i}$.

$\mathrm{Q}_{\mathrm{Gi}}=$ Total daya reaktif yang dibangkitkan oleh generator pada bus-i.

$\mathrm{Q}_{\mathrm{Di}}=$ Total daya aktif beban pada bus-i.

$\mathrm{V}_{\mathrm{i}}=$ Magnitud tegangan pada bus-i.

$\mathrm{V}_{\mathrm{j}}=$ Magnitud tegangan pada bus-i.

$\mathrm{g}_{\mathrm{ij}}=$ Konduktansi saluran antara bus-i dan bus-j.

$b_{\mathrm{ij}}=$ Suseptansi saluran antara bus-i dan bus-j.

$\theta_{\mathrm{ij}}=$ Perbedaan sudut tegangan antara bus $\mathrm{i}$ dan $\mathrm{j}$.

$\mathrm{n}_{\mathrm{b}}=$ Jumlah bus pada sistem.

\section{2) Batasan Generator}

Batasan pada generator merupakan variabel pada generator yang memiliki batasan nilai yang terdiri dari daya reaktif serta magnitud tegangan pada semua generator. Batasan ini diterapkan ke semua unit generator yang terkoneksi ke sistem, baik pada bus generator (PV Bus) maupun swing bus.

$$
\begin{aligned}
& Q_{G i}^{\min } \leq Q_{G i} \leq Q_{G i}^{\max }, \mathrm{I}=1, \ldots \ldots, \mathrm{N}_{\mathrm{G}} \\
& V_{G i}^{\min } \leq V_{G i} \leq V_{G i}^{\max }, \mathrm{I}=1, \ldots \ldots, \mathrm{N}_{\mathrm{G}}
\end{aligned}
$$

$\mathrm{Q}_{\mathrm{Gi}}$ merupakan daya reaktif yang dibangkitkan generator ke-i, $\mathrm{Q}_{\mathrm{Gi}}^{\min }$ dan $\mathrm{Q}_{\mathrm{Gi}}^{\max }$ secara berturut-turut merupakan batas minimal dan maksimal daya reaktif yang dimiliki generator ke-i. Sedangkan $\mathrm{V}_{\mathrm{Gi}}$ merupakan magnitud tegangan pada bus pembangkit ke-i, $\mathrm{V}_{\mathrm{Gi}}^{\min }$ dan $\mathrm{V}_{\mathrm{Gi}}^{\max }$ secara berturut-turut merupakan batas minimal dan maksimal magnitude tegangan pada bus pembangkit ke-i. $\mathrm{N}_{\mathrm{G}}$ merupakan jumlah pembangkit pada sistem.

\section{3) Batasan Transformator}

Batasan yang terdapat pada transformator yaitu nilai tap trafo dengan setting batas atas dan bawah seperti berikut:

$$
T_{i}^{\min } \leq T_{i} \leq T_{i}^{\max }, \mathrm{i}=1, \ldots \ldots, \mathrm{N}_{\mathrm{T}}
$$

$\mathrm{T}_{\mathrm{i}}$ merupakan rasio tap trafo pada unit trafo ke-i, $\mathrm{T}_{\mathrm{i}}^{\mathrm{min}}$ dan $\mathrm{T}_{\mathrm{i}}^{\max }$ secara berturut-turut merupakan batas minimal dan maksimal rasio tap trafo yang dimiliki unit trafo ke-i.

Nilai tap trafo akan mempengaruhi rasio trafo yang terkoneksi ke sistem tenaga listrik. Tap trafo bekerja untuk mempertahankan nilai tegangan pada sisi sekunder trafo agar bertahan pada tegangan yang diiinginkan saat tegangan pada sisi primer berubah. 


\section{4) Batasan Kompensator Daya Reaktif Shunt}

Kompensator daya reaktif shunt merupakan peralatan yang terpasang di bus yang mengkompensasi kebutuhan daya reaktif pada sistem tenaga listrik. Adapun kompensator tersebut memiliki kapasitas terpasangnya, sehingga daya reaktif yang dikompensasikan ke jaringan terbatas pada batas atas dan bawah seperti berikut:

$$
Q_{c i}^{\min } \leq Q_{c i} \leq Q_{c i}^{\max }, \mathrm{i}=1, \ldots \ldots, \mathrm{N}_{\mathrm{Qc}}
$$

$\mathrm{Q}_{\mathrm{ci}}$ merupakan daya reaktif yang dikompensasi dari kapasitor shunt ke-i, $\mathrm{Q}_{\mathrm{ci}}^{\min }$ dan $\mathrm{Q}_{\mathrm{ci}}^{\max }$ secara berturut-turut merupakan batas minimal dan maksimal daya reaktif yang dimiliki kapasitor shunt ke-i.

\section{5) Batasan Keamanan}

Batasan keamanan terdiri dari magnitud tegangan pada semua bus dan batasan kapasitas saluran pada sistem. Besarnya tegangan harus dalam kisaran yang diijinkan. Nilainilai ini harus dipertahankan untuk memastikan kualitas sistem tenaga listrik.

$$
V_{i}^{\text {min }} \leq V_{i} \leq V_{i}^{\max }, \mathrm{i}=1, \ldots \ldots, \mathrm{N}_{\text {bus }}
$$

$\mathrm{V}_{\mathrm{i}}$ merupakan nilai magnitud tegangan pada bus ke-i, nilai $\mathrm{V}_{\mathrm{i}}$ merupakan nilai magnitud tegangan di semua bus kecuali bus bus pembangkit. Batasan saluran digunakan untuk membatasi daya semu yang melewati setiap saluran tidak melebihi kapasitas maksimum.

$$
S_{i}<S_{i}^{\max }, \mathrm{i}=1, \ldots \ldots, \mathrm{N}_{\mathrm{L}}
$$

$\mathrm{S}_{\mathrm{i}}$ merupakan daya semu yang mengalir pada saluran ke-i. $\mathrm{N}_{\mathrm{L}}$ merupakan banyaknya saluran yang terdapat pada sistem. $\mathrm{S}_{\mathrm{i}}^{\max }$ merupakan batas maksimal daya semu yang mampu mengalir di saluran ke-i. $S_{i}^{\max }$ berkaitan dengan kemampuan tranfer daya maksimal di setiap saluran yang besarnya berbeda-beda.

Semua batasan dari (4) - (9) ditambahkan ke fungsi tujuan menggunakan fungsi penalti. Fungsi penalti diperoleh dengan mengalikan faktor penalti menjadi kuadrat perbedaan antara nilai variabel dan nilai batas. Solusi yang melanggar kendala akan memiliki nilai rugi daya saluran yang tinggi sehingga akan ditolak menjadi solusi terbaik. Secara matematis, fungsi penalti dinyatakan sebagai berikut:

$$
\begin{aligned}
\text { Penalti }= & \lambda_{\mathrm{P}}\left(P_{G 1}-P_{G 1}^{l i m}\right)^{2}+\lambda_{\mathrm{V}} \sum_{\mathrm{i}=1}^{\mathrm{Nbus}}\left(\mathrm{V}_{\mathrm{i}}-\mathrm{V}_{\mathrm{i}}^{\lim }\right)^{2} \\
& +\lambda_{\mathrm{Qg}} \sum_{\mathrm{i}=1}^{\mathrm{NG}}\left(\mathrm{Q}_{\mathrm{Gi}}-\mathrm{Q}_{\mathrm{Gi}}^{\lim }\right)^{2}+\lambda_{\mathrm{SL}} \sum_{\mathrm{i}=1}^{\mathrm{Nl}}\left(\mathrm{S}_{\mathrm{i}}-\mathrm{S}_{\mathrm{i}}^{\lim }\right)^{2}
\end{aligned}
$$

$\lambda_{\mathrm{P}}, \lambda_{\mathrm{V}}, \lambda_{\mathrm{Qg}}$, dan $\lambda_{\mathrm{SL}}$ adalah faktor penalti dari setiap variabel yang nilainya berbeda. Faktor hukuman dipilih dengan hatihati karena akan menentukan solusi terbaik. Sementara $X^{\mathrm{lim}}$ adalah nilai batas dari setiap variabel yang terdiri dari batas atas dan bawah. Jika nilai X lebih besar dari batas atas, maka $\mathrm{X}^{\mathrm{lim}}$ ditetapkan sebagai batas atas. Namun, jika nilai $\mathrm{X}$ lebih rendah dari batas bawah, maka $X^{\lim }$ ditetapkan sebagai batas bawah. Nilai batas dijelaskan sebagai berikut:

$$
\mathrm{X}^{\lim }=\left\{\begin{array}{l}
X^{\max } ; X>X^{\max } \\
X^{\operatorname{mim}} ; X<X^{\min }
\end{array}\right.
$$

\section{METODE}

\section{A. Aliran Daya}

Analisis tentang ORPD, tidak bisa terlepas dengan studi aliran daya itu sendiri yang secara umum dikenal sebagai aliran beban. Aliran daya diperlukan untuk tujuan perencanaan, penjadwalan ekonomis, dan pengontrolan pada sistem yang sudah ada, demikian juga untuk tujuan rencana pengembangan sistem. Masalah utamanya terdiri atas menentukan magnitud dan sudut fase tegangan pada setiap bus serta menentukan daya aktif dan reaktif di setiap saluran transmisi.

Dalam menyelesaikan suatu masalah aliran daya, sistem diasumsikan beroperasi pada kondisi stabil dan digunakan model satu fase. Empat parameter yang terkait dengan masing-masing bus, yaitu magnitud tegangan $|\mathrm{V}|$, sudut fase tegangan $\theta$, daya aktif $P$, dan daya reaktif $Q$.

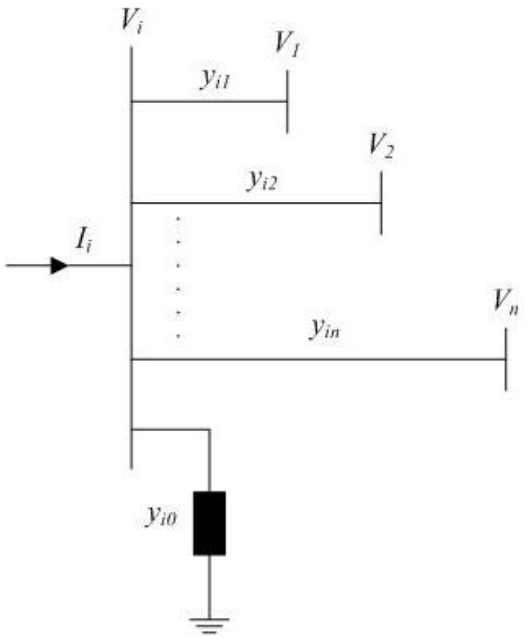

Gambar 1. Bus pada sistem tenaga listrik

Aplikasi Hukum Arus Kirchoff (HAK) pada Gambar 1 akan menghasilkan persamaan sebagai berikut:

$$
\begin{aligned}
I_{i} & =y_{i 0} V_{i}+y_{i 1}\left(V_{i}-V_{1}\right)+y_{i 2}\left(V_{i}-V_{2}\right)+\ldots . .+y_{i n}\left(V_{i}-V_{n}\right) \\
& =\left(y_{i 0}+y_{i 1}+y_{i 2}+\ldots .+y_{i n}\right) V_{i}-y_{i 1} V_{1}-y_{i 2} V_{2}-\ldots y_{i n} V_{n}
\end{aligned}
$$

atau

$$
I_{i}=V_{i} \sum_{j=0}^{n} y_{i j}-\sum_{j=1}^{n} y_{i j} V_{j} ; j \neq I
$$

Daya aktif dan reaktif yang mengalir pada bus-i dapat dihitung dengan:

$$
P_{i}+j Q_{i}=V_{i} I_{i}^{*}
$$

atau

$$
I_{i}=\frac{P_{i}-j Q_{i}}{V_{i}^{*}}
$$

Dimana y merupakan admitansi saluran, $\mathrm{V}$ merupakan magnitud tegangan, $\mathrm{P}$ merupakan daya aktif, $\mathrm{Q}$ merupakan daya reaktif dan I merupakan arus listrik yang mengalir pada saluran ke-i. 
Berdasarkan (12) - (15), formulasi matematis dari masalah aliran daya menghasilkan sistem dengan persamaan aljabar nonlinear yang harus diselesaikan dengan teknik iterasi. Setelah tegangan bus didapat dari solusi iteratif, langkah selanjutnya adalah menghitung arus yang melewati saluran dan rugi-rugi yang muncul pada jaringan, Gambar 2 memperlihatkan saluran yang terhubung dengan dua bus-i dan j.

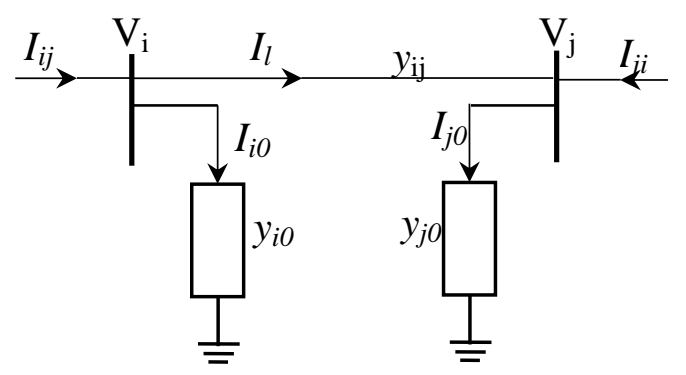

Gambar 2. Model saluran transmisi untuk menghitung arus saluran

Arus saluran $I_{i j}$ diukur pada bus $i$ dan didefinisikan positif dengan arah $i$ ke $j$ diberikan sebagai berikut:

$$
I_{i j}=I_{l}+I_{i 0}+=y_{i j}\left(V_{i}-V_{j}\right)+y_{i 0} V_{i}
$$

Sama seperti (16), arus saluran $I_{j i}$ diukur pada bus $j$ dan difenisikan positif dengan arah $j$ ke $i$ diberikan sebagai berikut:

$$
I_{j i}=-I_{l}+I_{j 0}+=y_{i j}\left(V_{j}-V_{i}\right)+y_{j 0} V_{j}
$$

Selanjutnya, daya kompleks $S_{i j}$ dari bus $i$ ke $j$ dan $S_{j i}$ dari bus $j$ ke $i$ adalah sebagai berikut:

$$
\begin{aligned}
& S_{i j}=V_{i} I_{i j}^{*} \\
& S_{j i}=V_{j} I_{j i}^{*}
\end{aligned}
$$

Rugi-rugi daya dalam saluran $i-j$ adalah penjumlahan aljabar dari aliran daya yang didapat dari (18) dan (19) sebagai berikut:

$$
S_{L i j}=S_{i j}+S_{j i}
$$

\section{B. Flower Pollination Algorithm (FPA)}

FPA adalah algoritma meta-heuristik yang terinspirasi oleh fenomena alam yang terkait dengan penyerbukan bunga. Proses polinasi, hubungan spesifik, dan sifat polinator dapat diidealkan menjadi 4 aturan yaitu [8]:

1. Polinasi silang dan biotik dianggap sebagai proses polinasi global dengan polinator pembawa serbuk sari melakukan gerak levy.

2. Polinasi sendiri dan abiotik dianggap sebagai polinasi lokal.

3. Hubungan spesifik bunga dengan polinator dianggap sebagai kemungkinan reproduksi, proporsional terhadap kemiripan dua bunga.

4. Polinasi lokal dan polinasi global dikendalikan dengan kemungkinan pergantian, karena pendekatan fisik dan faktor lain seperti angin, polinasi lokal dapat memiliki pecahan yang signifikan (p) pada keseluruhan aktivitas polinasi.
Dua langkah kunci pada algoritma ini yaitu polinasi global dan polinasi lokal. Pada langkah polinasi global, serbuk sari dibawa oleh polinator dan dapat berpindah dengan jarak yang jauh. Hal ini memastikan polinasi dan reproduksi yang paling optimal (nilai fitness terbaik) dan nilai fitness tersebut direpresentasikan sebagai $g *$. Aturan pertama sekaligus hubungan spesifik bunga dapat direpresentasikan secara matematis sebagai berikut:

$$
x_{i}^{t+1}=x_{i}^{t}+L\left(x_{i}^{t}-g^{*}\right)
$$

$x_{i}^{t+1}$ adalah serbuk sari i atau vektor solusi $x$ pada iterasi ke-t dan $g^{*}$ adalah solusi terbaik terbaru dari semua solusi pada generasi atau iterasi terbaru. Parameter $L$ adalah kekuatan polinasi, yang secara esensial adalah ukuran langkah. Karena serangga sebagai polinator mungkin bergerak pada jarak yang jauh dengan berbagai ukuran langkah, gerak levy digunakan untuk merepresentasikan karakteristik ini. Persamaan $L>0$ diambil dari distribusi levy.

Pada polinasi lokal atau aturan kedua, hubungan spesifik bunga direpresentasikan sebagai:

$$
x_{i}^{t+1}=x_{i}^{t}+\in\left(x_{j}^{t}-x_{k}^{t}\right)
$$

$x_{j}^{t}$ dan $x_{k}^{t}$ adalah serbuk sari dari bunga yang lain pada jenis yang sama. Secara matematis, jika $x_{j}^{t}$ dan $x_{k}^{t}$ datang dari jenis yang sama atau dipilih dari populasi yang sama, akan menjadi langkah acak lokal jika nilai $\epsilon$ merupakan distribusi seragam dari 0 hingga 1. Langkah-langkah optimisasi permasalahan ORPD menggunakan FPA dijelaskan sebagai berikut:

Langkah-1: Inisialisasi parameter data bus, data saluran, dan data beban. Tetapkan batas atas dan bawah dari setiap variabel.

Langkah-2: Membangkitkan populasi awal secara acak.

Langkah-3: Menjalankan analisis aliran daya dengan metode Newton-Raphson untuk setiap solusi.

Langkah-4: Menghitung rugi daya nyata pada saluran menggunakan (20).

Langkah-5: Hasil aliran daya dievaluasi dengan fungsi penalti sesuai dengan (10).

Langkah-6: Simpan solusi terbaik dari pembangkitan populasi awal.

Langkah-7: Mulai iterasi dengan metode FPA. Jika probability switch < nilai acak maka melakukan penyerbukan Global. Jika tidak, lakukan penyerbukan lokal.

Langkah-8: Hitung nilai fungsi tujuan dari setiap solusi baik melalui penyerbukan lokal atau global.

Langkah-9: Evaluasi fungsi objektif menggunakan fungsi penalti sesuai dengan (11).

Langkah-10: Ulangi hingga jumlah iterasi maksimum, simpan solusi terbaik.

Analogi penerapan permasalahan ORPD menggunakan FPA dapat dilihat pada Gambar 3. Diagram alir untuk metode FPA dapat dilihat pada Gambar 4. 


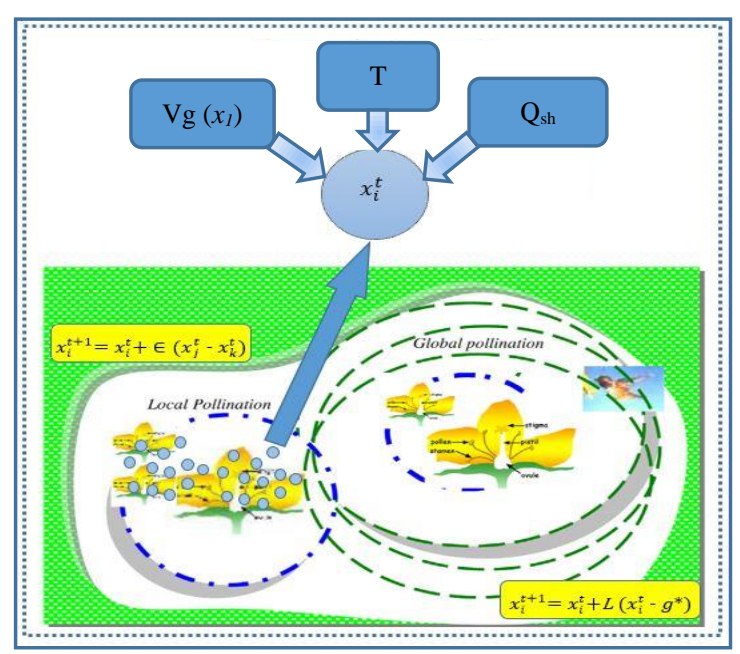

Gambar 3. Analogi penerapan FPA pada permasalahan ORPD

\section{Tes Sistem IeEe-30 Bus}

Sistem IEEE 30 bus adalah sistem standar yang digunakan untuk membuktikan akurasi dari metode yang diusulkan. Sistem ini mempunyai 6 pembangkit thermal, 30 bus, 41 saluran, dengan total beban sebesar 283,4 MW [14]. Pada permasalahan ORPD ini, terdapat 19 variabel pengontrolan, yaitu: enam unit magnitud tegangan pada generator, empat pengaturan tap transformator, dan sembilan injeksi kapasitor [15]-[18]. Enam magnitud tegangan generator yang diatur yaitu pembangkit pada bus $1,2,5,8,11$, dan 13. Keenam magnitud tegangan tersebut merupakan semua unit bus pembangkit termasuk swing bus. Empat pengaturan tap transformator terletak pada saluran bus 6 ke bus 9, bus 6 ke bus 10, bus 4 ke bus 12 dan bus 28 ke bus 27. Sedangkan sembilan injeksi kapasitor terletak pada bus 10, 12, 15, 17, 20, 21, 23, 24, dan 29. Diagram satu garis sistem IEEE 30 bus ditunjukkan pada Gambar 5.

Data generator ditunjukan pada Tabel I. Data generator berisi informasi tentang kapasitas maksimal dan minimal dari daya nyata serta daya reaktif yang dapat dibangkitkan oleh tiap pembangkit. Data tersebut digunakan saat melakukan aliran daya yang mana daya yang dibangkitkan oleh tiap generator baik daya nyata maupun daya reaktif harus dalam rentang yang sesuai dengan kapasitas generator itu sendiri.

Data saluran disajikan dalam satuan (p.u) dengan basis 100 MVA. Data generator, parameter saluran dan beban merujuk pada literatur sebelumnya [14]. Bus tegangan dalam sistem memiliki batas bawah 0,95 pu untuk semua bus. Sedangkan batas atas 1,05 p.u dan 1,1 p.u untuk bus PQ dan PV secara berturut-turut [15], [17], [19], [20]. Kondisi awal sebelum optimasi merujuk pada literatur [16].

Parameter dari FPA yang digunakan dalam penelitian ini adalah ukuran populasi 20 , dimensi 19 , probability switch 0,8 , dan jumlah maksimum generasi total 10.000 .

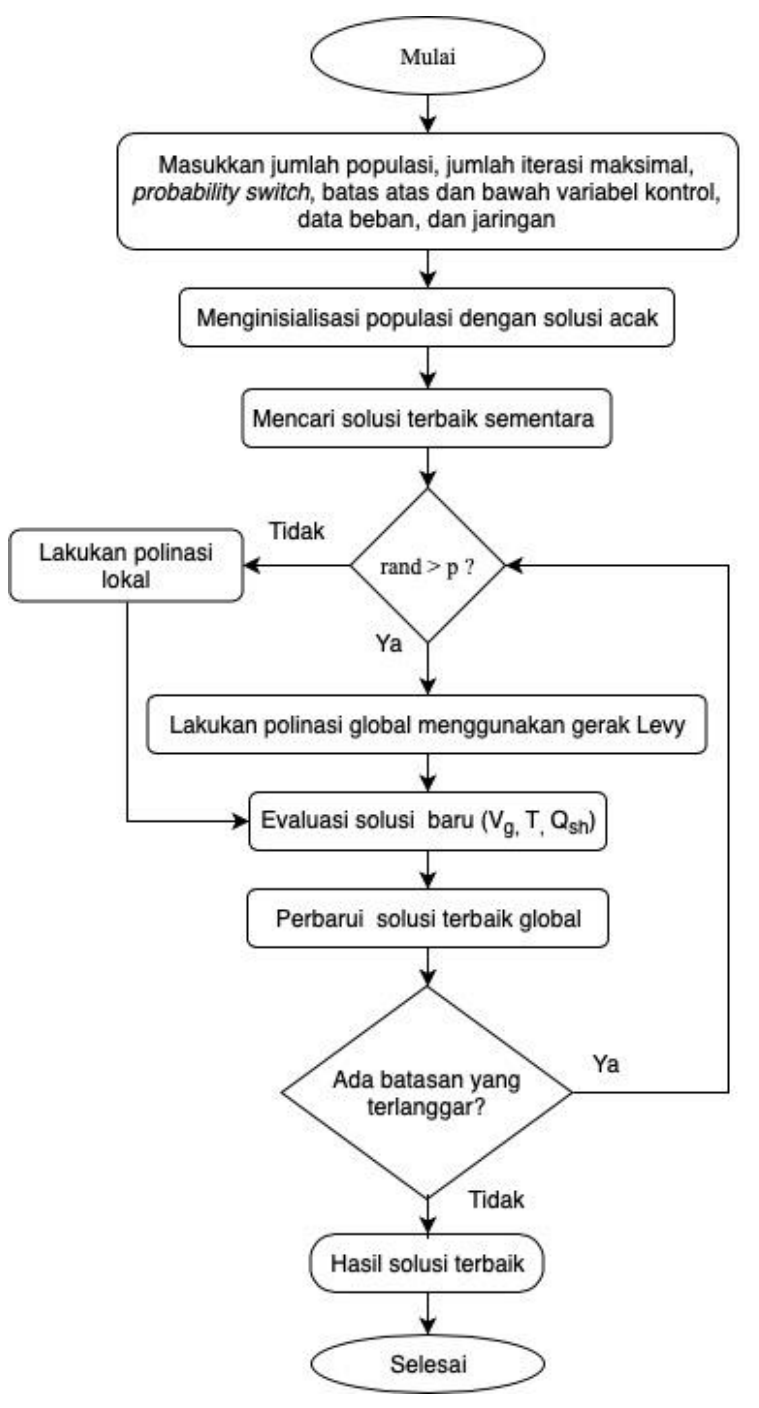

Gambar 4. Diagram alir ORPD menggunakan FPA

TABEL I. DATA GENERATOR SISTEM IEEE-30 BUS

\begin{tabular}{|c|c|c|c|c|c|}
\hline No & $\begin{array}{c}\text { Nomor } \\
\text { Bus }\end{array}$ & $\begin{array}{c}\mathbf{P}_{\text {Gmin }} \\
(\mathbf{M W})\end{array}$ & $\begin{array}{c}\mathbf{P}_{\text {Gmax }} \\
(\mathbf{M W})\end{array}$ & $\begin{array}{c}\mathbf{Q}_{\text {Gmin }} \\
\text { (MVar) }\end{array}$ & $\begin{array}{c}\mathbf{Q}_{\text {Gmax }} \\
(\mathbf{M V a r})\end{array}$ \\
\hline 1. & 1 & 50 & 200 & -20 & 150 \\
\hline 2. & 2 & 20 & 80 & -20 & 60 \\
\hline 3. & 5 & 15 & 50 & -15 & 62,45 \\
\hline 4. & 8 & 10 & 35 & -15 & 48,73 \\
\hline 5. & 11 & 10 & 30 & -10 & 40 \\
\hline 6. & 13 & 12 & 40 & -15 & 44,72 \\
\hline
\end{tabular}




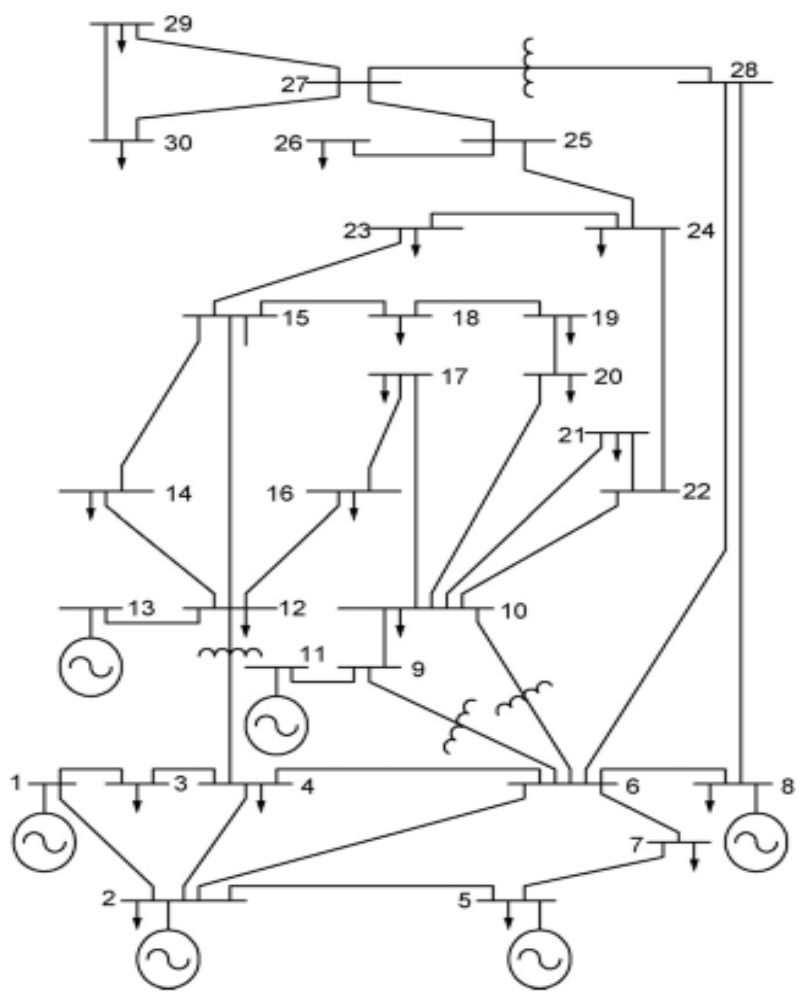

Gambar 5. Diagram garis tunggal tes sistem IEEE-30 bus

\section{HASIL DAN PEMBAHASAN}

Simulasi dilakukan 10 kali untuk menentukan ketahanan metode yang diusulkan. Hasil variabel kontrol ditunjukkan pada Tabel II. Semua nilai variabel kontrol tidak melewati ambang batas minimum dan maksimum.

Rugi daya saluran rata-rata untuk 10 kali percobaan adalah 4,911 MW dengan standar deviasi 0,0257. Hasil terbaik yang diperoleh yaitu pada trial 2 dengan rugi daya nyata sebesar 4,895 MW. Sementara hasil terburuk diperoleh di trial 1 dengan rugi daya nyata sebesar 4,967 MW. Setelah dilakukan optimasi, magnitud tegangan di semua bus tidak melewati ambang batas yang diijinkan yang ditunjukkan pada Gambar 6 .

Besarnya tegangan terendah 1,0147 p.u terletak di bus 11 . Sedangkan yang tertinggi adalah 1,0716 p.u yang terletak di bus 1. Daya reaktif yang dihasilkan atau dikonsumsi oleh generator masih dalam kisaran yang diijinkan seperti yang ditunjukkan pada Tabel III. Pembangkitan bernilai positif berarti generator menghasilkan daya reaktif. Sedangkan pembangkitan bernilai negatif berarti generator mengkonsumsi daya reaktif.

TABEL II. OPTIMAL SETTING DARI VARIABEL KONTROL

\begin{tabular}{|c|c|c|c|c|c|c|c|c|c|c|c|c|c|c|}
\hline No & $\begin{array}{l}\text { Variabel } \\
\text { Kontrol }\end{array}$ & Min. & Max. & $\begin{array}{c}\begin{array}{c}\text { Kondisi } \\
\text { awal }\end{array} \\
\end{array}$ & $\begin{array}{c}\text { Trial } \\
1\end{array}$ & $\begin{array}{c}\text { Trial } \\
2 \\
\end{array}$ & $\begin{array}{c}\text { Trial } \\
\mathbf{3} \\
\end{array}$ & $\begin{array}{c}\text { Trial } \\
\mathbf{4} \\
\end{array}$ & $\begin{array}{c}\text { Trial } \\
5\end{array}$ & $\begin{array}{c}\text { Trial } \\
6\end{array}$ & $\begin{array}{c}\text { Trial } \\
7 \\
\end{array}$ & $\begin{array}{c}\text { Trial } \\
8 \\
\end{array}$ & $\begin{array}{c}\text { Trial } \\
9\end{array}$ & $\begin{array}{c}\text { Trial } \\
10\end{array}$ \\
\hline 1 & $\mathrm{~V}_{1}$ (p.u) & 0,95 & 1,1 & 1,05 & 1,0722 & 1,0716 & 1,0715 & 1,0716 & 1,0711 & 1,0724 & 1,0715 & 1,0714 & 1,0716 & 1,0724 \\
\hline 2 & $\mathrm{~V}_{2}$ (p.u) & 0,95 & 1,1 & 1,04 & 1,0538 & 1,0424 & 1,0527 & 1,0625 & 1,0622 & 1,0528 & 1,0626 & 1,0624 & 1,0625 & 1,0433 \\
\hline 3 & $\mathrm{~V}_{5}(\mathrm{p} \cdot \mathrm{u})$ & 0,95 & 1,1 & 1,01 & 1,0407 & 1,04 & 1,0403 & 1,0405 & 1,0408 & 1,0412 & 1,0413 & 1,0404 & 1,0405 & 1,0409 \\
\hline 4 & $\mathrm{~V}_{8}(\mathrm{p} \cdot \mathrm{u})$ & 0,95 & 1,1 & 1,01 & 1,0814 & 1,077 & 1,0669 & 1,0582 & 1,0769 & 1,0674 & 1,0672 & 1,0582 & 1,0582 & 1,0821 \\
\hline 5 & $\mathrm{~V}_{11}$ (p.u) & 0,95 & 1,1 & 1,05 & 0,9948 & 0,9747 & 0,9835 & 1,0066 & 0,9713 & 0,9826 & 0,9836 & 1,0069 & 1,0066 & 0,9992 \\
\hline 6 & $\mathrm{~V}_{13}$ (p.u) & 0,95 & 1,1 & 1,05 & 1,0449 & 1,0502 & 1,0503 & 1,0419 & 1,0512 & 1,0417 & 1,0496 & 1,0426 & 1,0419 & 1,041 \\
\hline 7 & $\mathrm{~T}_{11}$ (p.u) & 0,9 & 1,1 & 1,078 & 0,9785 & 1,0203 & 1,0202 & 1,0234 & 1,0196 & 1,0216 & 1,018 & 1,0232 & 1,0234 & 0,9681 \\
\hline 8 & $\mathrm{~T}_{12}$ (p.u) & 0,9 & 1,1 & 1,069 & 31 & 0,9001 & 0,9003 & 00 & 0,9 & 0,9 & 0,9 & 0, & 0,9 & 0,9472 \\
\hline 9 & $\mathrm{~T}_{15}$ (p.u) & 0,9 & 1,1 & 1,032 & 0,9697 & 0,9767 & 0,9769 & 0,9727 & 0,9789 & 0,9721 & 0,9756 & 0,9735 & 0,9727 & 0,9664 \\
\hline 10 & $\mathrm{~T}_{36}$ (p.u) & 0,9 & 1,1 & 1,068 & 0,9749 & 0,9729 & 0,9714 & 0,9727 & 0,9757 & 0,9768 & 0,9802 & 0,9729 & 0,9727 & 0,9739 \\
\hline 11 & $\mathrm{Q}_{\mathrm{c} 10}(\mathrm{MVar})$ & 0 & 5 & 0 & 3,8338 & 4,998 & 4,8663 & 4,979 & 4,8446 & 4,9851 & 4,3417 & 4,9963 & 4,979 & 0,2217 \\
\hline 12 & $\mathrm{Q}_{\mathrm{c} 12}(\mathrm{MVar})$ & 0 & 5 & 0 & 4,0292 & 0,2639 & 0,4547 & 4,9952 & 1,2302 & 4,3776 & 2,0855 & 4,9505 & 4,9952 & 2,5873 \\
\hline 13 & $\mathrm{Q}_{\mathrm{c} 15}(\mathrm{MVar})$ & 0 & 5 & 0 & 1,9899 & 4,9692 & 4,8731 & 4,4593 & 4,8191 & 4,8236 & 3,8412 & 4,3622 & 4,4593 & 4,5647 \\
\hline 14 & $\mathrm{Q}_{\mathrm{c} 17}(\mathrm{MVar})$ & 0 & 5 & 0 & 0,9326 & 4,9991 & 4,8795 & 4,9987 & 4,8753 & 4,926 & 4,9566 & 4,999 & 4,9987 & 4,8619 \\
\hline 15 & $\mathrm{Q}_{\mathrm{c} 20}(\mathrm{MVar})$ & 0 & 5 & 0 & 2,4523 & 4,4143 & 4,7169 & 4,4859 & 4,1618 & 4,8318 & 3,2438 & 4,2735 & 4,4859 & 3,596 \\
\hline 16 & $\mathrm{Q}_{\mathrm{c} 21}(\mathrm{MVar})$ & 0 & 5 & 0 & 4,3298 & 5 & 4,9875 & 4,9997 & 4,9972 & 4,9772 & 4,9918 & 4,9992 & 4,9997 & 4,9754 \\
\hline 17 & $\mathrm{Q}_{\mathrm{c} 23}(\mathrm{MVar})$ & 0 & 5 & 0 & 2,9806 & 3,0399 & 2,9844 & 3,0418 & 2,9542 & 3,8079 & 3,818 & 3,1655 & 3,0418 & 3,0991 \\
\hline 18 & $\mathrm{Q}_{\mathrm{c} 24}(\mathrm{MVar})$ & 0 & 5 & 0 & 4,7792 & 5 & 4,9877 & 4,9992 & 4,9944 & 4,9595 & 4,8583 & 4,9989 & 4,9992 & 5 \\
\hline \begin{tabular}{|l|}
19 \\
\end{tabular} & $\mathrm{Q}_{\mathrm{c} 29}$ (MVar) & 0 & 5 & 0 & 1,6537 & 1,7941 & 1,4525 & 1,6688 & 1,9289 & 2,3475 & 2,13 & 1,6301 & 1,6688 & 1,5741 \\
\hline \multicolumn{4}{|c|}{ Rugi Saluran (MW) } & 5,82 & 4,967 & 4,895 & 4,896 & 4,903 & 4,896 & 4,898 & 4,899 & 4,903 & 4,903 & 4,951 \\
\hline
\end{tabular}




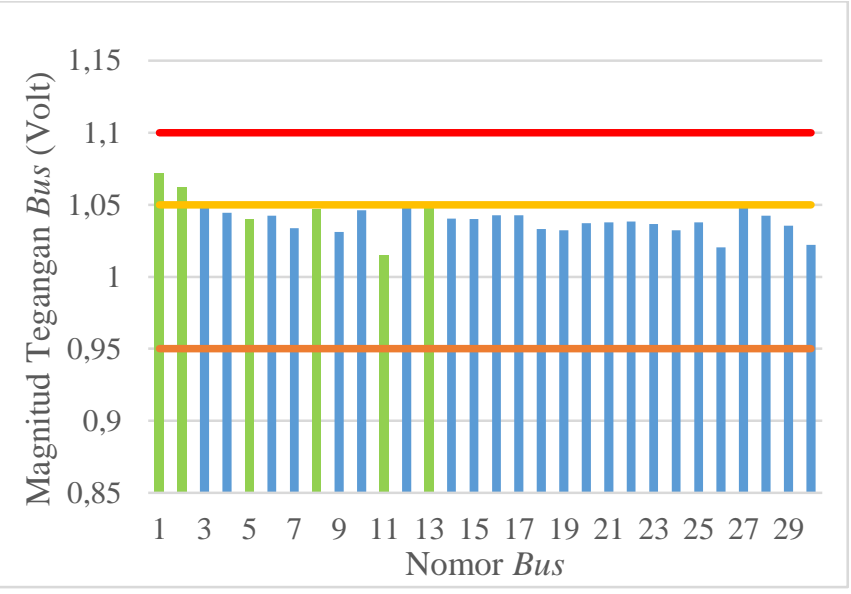

Gambar 6. Magnitud tegangan sistem IEEE-30 bus setelah optimasi

Kapasitas saluran untuk mengalirkan daya pada perhitungan ORPD menjadi salah satu batasan yang harus diperhatikan. Pada kebanyakan referensi [5]-[7], [21], [22] batasan kapasitas saluran hanya dijaga agar tidak melebihi kemampuan maksimalnya. Hal itu pula yang dilakukan pada penelitian ini. Pembebanan saluran tidak mempertimbangkan faktor berkurangnya fungsi kinerja dari saluran apabila dibebani dengan nilai persentase pembebanan yang tinggi dan dilakukan dalam waktu yang relatif lama. Kondisi pembebanan saluran setelah dilakukan optimisasi menggunakan metode FPA dapat dilihat pada Gambar 7. Nilai pembebanan saluran tertinggi sebesar $83,19 \%$ yang terjadi pada saluran nomor 12 yaitu antara bus 6 dan bus 10 . Sedangkan persentase pembebanan saluran yang paling rendah terjadi pada saluran nomor 8 yaitu antara bus 5 dan bus 7 dengan niai pembebanan sebesar 6,29\%.

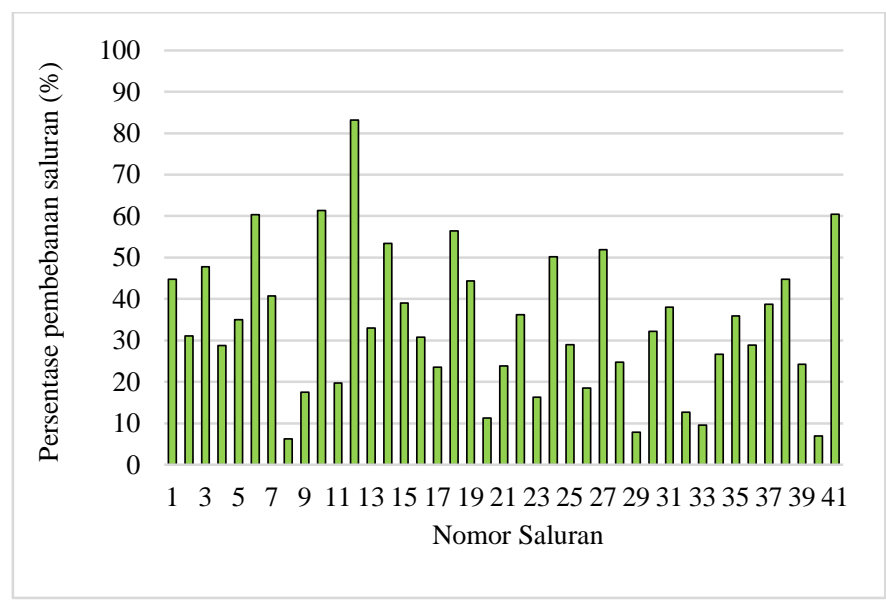

Gambar 7. Presentase pembebanan saluran setelah optimasi

Konvergensi pada suatu proses optimisasi merupakan hal yang penting untuk diperhatikan, hal ini untuk menunjukkan sejauh mana nilai dari fungsi tujuan tersebut merupakan nilai yang paling minimal atau maksimal yang sudah relatif konstan dan tidak ada lagi perubahan yang signifikan. Gambar 8 menunjukkan grafik konvergensi dari total biaya pembangkit dengan metode FPA pada percobaan ke-2 yang merupakan hasil terbaik dari 10 kali percobaan. Perbandingan dengan metode lain menunjukkan hasil yang memuaskan seperti yang ditunjukkan pada Tabel IV.

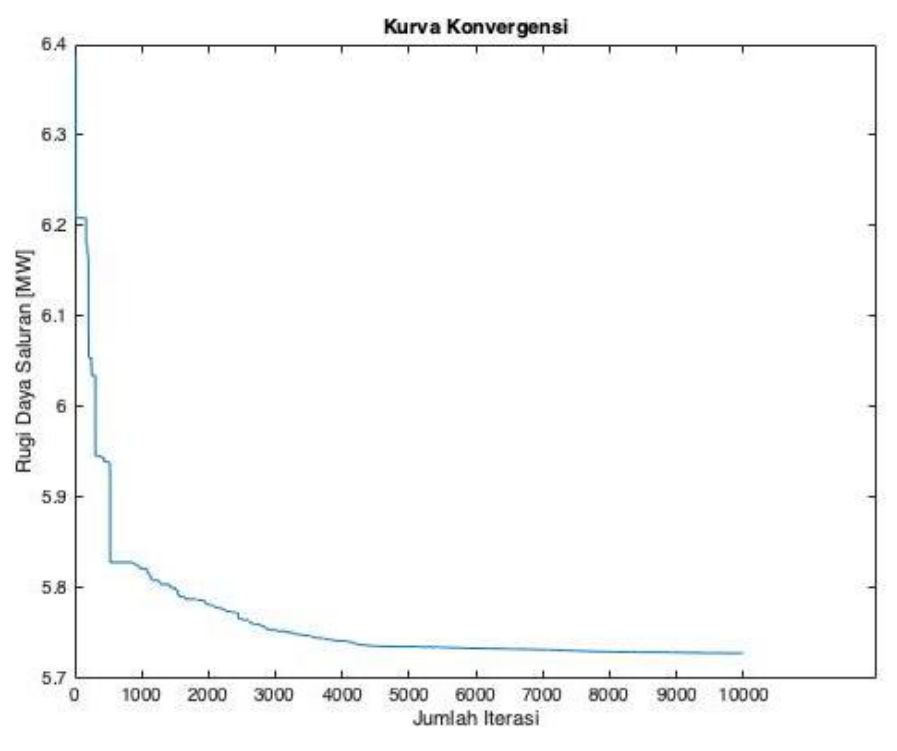

Gambar 8. Kurva konvergensi FPA

TABEL III. PEMBANGKITAN DAYA REAKTIF

\begin{tabular}{|c|c|c|c|}
\hline \multirow{2}{*}{$\begin{array}{c}\text { Nomor } \\
\text { bus }\end{array}$} & \multicolumn{3}{|c|}{ Daya Reaktif (MVar) } \\
\cline { 2 - 4 } & Minimal & Maksimal & Pembangkitan \\
\hline 1 & -20 & 150 & $-2,802$ \\
\hline 2 & -20 & 60 & 11,075 \\
\hline 5 & -15 & 62,45 & 21,779 \\
\hline 8 & -15 & 48,73 & 43,865 \\
\hline 11 & -10 & 40 & $-7,691$ \\
\hline 13 & -15 & 44,72 & 0,380 \\
\hline
\end{tabular}

TABEL IV. Perbandingan DEngan Berbagai Metode

\begin{tabular}{|c|l|c|}
\hline No & \multicolumn{1}{|c|}{ Metode } & $\begin{array}{c}\text { Rugi daya } \\
\text { (MW) }\end{array}$ \\
\hline 1. & Algoritma Genetik [5] & 5,00954 \\
\hline 2. & PSO [5] & 4,91578 \\
\hline 3. & FPA & 4,895 \\
\hline
\end{tabular}

\section{Penutup}

Dalam penelitian ini metode FPA diusulkan untuk memecahkan masalah ORPD pada sistem uji IEEE-30 bus. Sistem ini memiliki 30 bus, 6 unit generator, 4 trafo dan 41 saluran transmisi. FPA digunakan untuk menemukan rugi daya nyata pada saluran yang paling minimal. Variabel kontrol adalah magnitud tegangan pada PV dan swing bus, rasio pengaturan tap transformator, dan nilai kapasitansi shunt dengan beberapa batasan yang ada pada sistem tersebut. Metode FPA menunjukkan kinerja yang memuaskan. Metode FPA terbukti mengurangi rugi daya saluran dari 5,82 MW menjadi 4,895 MW atau sebesar $15,89 \%$. Hasil tersebut juga menunjukkan nilai yang lebih baik jika dibandingkan dengan Algoritma Genetik dan PSO. 


\section{REFERENSI}

[1] G. B. Allen J. Wood, Bruce F. Wollenberg, Power Generation, Operation, and Control, Third edit. Hoboken, New Jersey: John Wiley \& Sons, Inc., 2013.

[2] W. G. on L. R. CIRED, "Reduction of Technical and Non-Technical Losses in Distribution Networks," Int. Conf. Electr. Distrib., p. 114, 2017.

[3] M. A. Abido, "Multiobjective Optimal VAR Dispatch using strength Pareto Evolutionary Algorithm," Evol. Comput. 2006. CEC 2006. IEEE Congr., pp. 730-736, 2006.

[4] M. Ghasemi, S. Ghavidel, M. M. Ghanbarian, and A. Habibi, "A New Hybrid Algorithm for Optimal Reactive Power Dispatch Problem with discrete and Continuous Control Variables," Appl. Soft Comput. J., vol. 22, pp. 126-140, 2014.

[5] G. Chen, L. Liu, Z. Zhang, and S. Huang, "Optimal reactive Power Dispatch by Improved GSA-based Algorithm with the Novel Strategies to Handle Constraints," Appl. Soft Comput. J., vol. 50, pp. 58-70, 2017.

[6] S. Duman, Y. Sönmez, U. Güvenç, and N. Yörükeren, "Optimal Reactive Power Dispatch using a gravitational Search Algorithm," IET Gener. Transm. Distrib., vol. 6, no. 6, pp. 563-576, 2012.

[7] A. H. Khazali and M. Kalantar, "Optimal Reactive Power Dispatch based on Harmony Search Algorithm," Int. J. Electr. Power Energy Syst., vol. 33, no. 3, pp. 684-692, 2011.

[8] X.-S. Yang, "Flower Pollination Algorithm for Global Optimization," Unconv. Comput. Nat. Comput. 2012, Lect. Notes Comput. Sci., vol. 7445, pp. 240-249, 2012.

[9] B. Mahdad and K. Srairi, "Security constrained Optimal Power Flow Solution using New Adaptive Partitioning Flower Pollination Algorithm," Appl. Soft Comput., vol. 46, pp. 501-522, 2016.

[10] B. S. Kumar, M. Suryakalavathi, and G. V. N. Kumar, "Optimal Power Flow with Static VAR Compensator based on Flower Pollination Algorithm to Minimize Real Power Losses," Conf. Power, Control. Commun. Comput. Technol. Sustain. Growth, PCCCTSG 2015, no. 2, pp. 112-116, 2016.

[11] S. Vijayaraj and R. K. Santhi, "Multi-area Economic Dispatch using Flower Pollination Algorithm," Electr. Electron. Optim. Tech. (ICEEOT), Int. Conf., pp. 4355-4360, 2016.
[12] E. S. Oda, A. A. Abdelsalam, M. N. Abdel-Wahab, and M. M. El Saadawi, "Distributed Generations Planning using Flower Pollination Algorithm for Enhancing Distribution System Voltage Stability," Ain Shams Eng. J., vol. 8, no. 4, pp. 593-603, 2017.

[13] A. Y. Abdelaziz, E. S. Ali, and S. M. Abd Elazim, "Implementation of Flower Pollination Algorithm for Solving Economic Load Dispatch and Combined Economic Emission Dispatch Problems in Power Systems," Energy, vol. 101, pp. 506-518, 2016.

[14] O. Alsac and B. Stott, "Optimal Load Flow with Steady-State Security," IEEE Trans. Power Appar. Syst., vol. PAS-93, no. 3, pp. 745-751, 1974.

[15] A. A. Abou El Ela, M. A. Abido, and S. R. Spea, "Optimal Power Flow using Differential Evolution Algorithm," Electr. Power Syst. Res., vol. 80, no. 7, pp. 878-885, 2010.

[16] K. Y. Lee, Y. M. Park, and J. L. Ortiz, "A United Approach to Optimal Real and Reactive Power Dispatch,” IEEE Trans. Power Appar. Syst., vol. PAS-104, no. 5, pp. 1147-1153, 1985.

[17] M. A. Abido, "Optimal Power Flow using Particle Swarm Optimization," Int. J. Electr. Power Energy Syst., vol. 24, no. 7, pp. 563-571, 2002.

[18] S. Surender Reddy and C. Srinivasa Rathnam, "Optimal Power Flow using Glowworm Swarm Optimization," Int. J. Electr. Power Energy Syst., vol. 80, pp. 128-139, 2016.

[19] I. Oumarou, P. D. Jiang, and P. C. Yijia, "Particle Swarm Optimization Applied to Optimal Power Flow Solution," no. 2, 2009.

[20] A.-A. A. Mohamed, Y. S. Mohamed, A. A. M. El-Gaafary, and A. M. Hemeida, "Optimal Power Flow using Moth Swarm Algorithm," Electr. Power Syst. Res., vol. 142, pp. 190-206, 2017.

[21] A. Rajan and T. Malakar, "Exchange Market Algorithm based Optimum Reactive Power Dispatch," Appl. Soft Comput. J., vol. 43, pp. 320-336, 2016

[22] B. Shaw, V. Mukherjee, and S. P. Ghoshal, "Solution of Reactive Power Dispatch of Power Systems by an Opposition-based Gravitational Search Algorithm," Int. J. Electr. Power Energy Syst., vol. 55, pp. 29-40, 2014. 